Please do not remove this page

RMIT

UNIVERSITY

\title{
New visualities and the digital wayfarer: Reconceptualizing camera phone photography and locative media
}

Hjorth, Larissa; Pink, Sarah

https://researchrepository.rmit.edu.au/esploro/outputs/9921859726901341/filesAndLinks?institution=61RMIT_INST\&index=null

Hjorth, L., \& Pink, S. (2014). New visualities and the digital wayfarer: Reconceptualizing camera phone photography and locative media. Mobile Media and Communication, 2(1), 40-57.

https://doi.org/10.1177/2050157913505257

Document Version: Submitted Version

Published Version: https://doi.org/10.1177/2050157913505257

Repository homepage: https://researchrepository.rmit.edu.au

(c) The Author(s) 2014

Downloaded On 2023/04/27 00:48:19 +1000

Please do not remove this page 
Thank you for downloading this document from the RMIT Research Repository.

The RMIT Research Repository is an open access database showcasing the research outputs of RMIT University researchers.

RMIT Research Repository: http://researchbank.rmit.edu.au/

\section{Citation:}

Hjorth, L and Pink, S 2014, 'New visualities and the digital wayfarer: Reconceptualizing camera phone photography and locative media', Mobile Media \& Communication, vol. 2, no. 1 , pp. 40-57.

See this record in the RMIT Research Repository at:

http://researchbank.rmit.edu.au/view/rmit:22897

Version: Submitted Version

Copyright Statement: (C) The Author(s) 2014

Link to Published Version:

http://dx.doi.org/10.1177/2050157913505257 


\title{
New Visualities and the Digital Wayfarer: \\ Reconceptualizing the place of camera phone photography \\ Larissa Hjorth and Sarah Pink
}

\begin{abstract}
In this article, we examine how second generation locative media and emerging contemporary camera phone practices are becoming entangled to create new visualities and socialities of place and place making. Location-based services (LBS) have become an important part of smartphone camera apps like Instagram. Geotagging is increasingly the default, rather than choice, for many mobile applications, especially camera phone apps. This has transformed both how we experience and conceptualize online and offline relationships across micro and macro realms and how we chart these relationships and environments as we move through the everyday world.
\end{abstract}

Through a preliminary study of ten users of smartphones in urban Australia we explore how camera phone and LBS practices become part of everyday life. In Australia, mobile internet subscriptions have now reached 22.1 million: basically one subscription for every person in the country (ACMA 2013). To understand these new everyday visualities we develop the notion of the 'digital wayfarer' as a way to think about the perpetually moving mobile media user. Expanding upon Tim Ingold's notion of the wayfaring type of mobility that is both routine and repetitive (i.e. 'transport') in the realm of the digital interwoven within the everyday, we reflect upon the digital wayfarer as they move through taking and sharing pictures and their tagged geographic and temporal contexts as part of broader emplaced and interwoven visualities and socialities.

Keywords: locative media, smartphones, camera phones, networked visuality, location-based services (LBS) 


\section{Introduction: A glance into the world of emplaced visuality}

I choose when I allow an application to tag my location-sometimes I find it too intrusivetoo public... and at other times I want to have context for the images and moments I've captured on the fly. It helps me remember beyond the image frame... I love the fact that stories and moments can now be attached to place... That we are no longer wandering around the world alone - that our shared experiences have made a kind of virtual fabric.... I want to see a thicker and richer document of life produced as a result of locative media - this idea of a life fabric that comes to mind really does seem like a tangible /possible thing. Something that lives in space and time, that's as important as a heritage building to preserve- like a footprint for the future ("Barbara", aged 35).

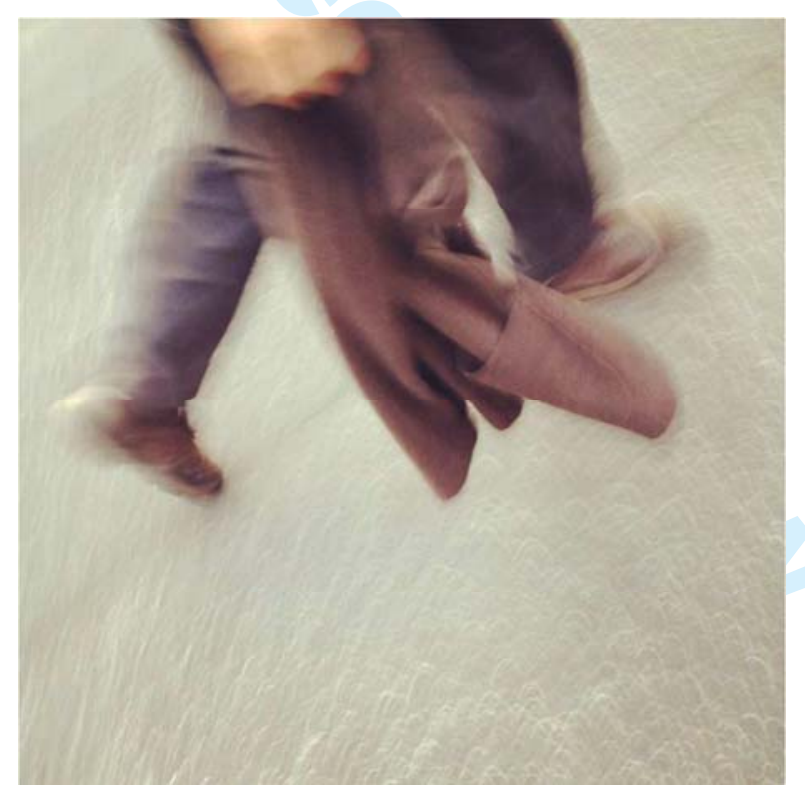

Figure 1: Barbara's emplaced Visuality:

“Accidental trigger finger captures a peak hour moment with a stranger" 
For Barbara, who lives in Melbourne (Australia), camera phone applications (apps) like Instagram are an embedded part of her everyday media practices. She loves the overlay of location-based services (LBS) with camera phone apps. On average, Barbara takes a picture via Instagram at least twice a day. She views the application as a succinct way to mark a place and time for both her own personal memory and also as a sign as part of her journey throughout life. Her series of image-inmotion visualities are an embedded part of her everyday movements whereby accidents, such as the "trigger finger", are welcomed, shared and archived as part of her personal diary.

Thousands of miles away, in a busy café in Seoul's Shinchon area, a young woman drinks coffee. Far from bored or lonely, Soo touches her smartphone like an old friend. After "checking in" on the mobile game, I love Coffee, to show others where she is, she begins to explore her various smartphone photo apps. Soo used to take self-portraits ( $s e l-c a$ ) and upload them to Kakaotalk story that features an online room where co-present friends hang out (much like Korea's oldest social network site, Cyworld minihompy). In I love Coffee, place is an important motivation for sharing camera phone images. Talking about where you are is an excuse to talk and share with your absent co-present (Gergen 2002) friends. Echoing the sentiment of the postcard, sharing camera phone images says, "I'm here and I want to share it with you" (Hjorth 2005).

The ongoing significance of place in informing mobile media practices, much like first conversations on mobile phones that were dominated with localized forms of "where are you?", continues to haunt through other forms. Through sharing playful pictures of places as part of everyday movements, camera phone practices provide new ways of mapping place beyond just the geographic: they partake in adding social, emotional, psychological and aesthetic dimensions to a sense of place. Camera phone sharing shows the importance of co-presence sociality in the practice of place as something more than 
just geographic or physical. With the promise of location-based services becoming increasingly embedded within smartphone photo apps through geotagging as a norm, the types of camera phone images that are taken and shared are changing in what they say about place. While apps like Instagram and Facebook might seem to privilege the role of locative media through almost default geotagging settings, the uptake of locative media still resides in uneven and often tacit forms

Likewise Barbara's camera phone practices have changed over time. Her avid enthusiasm for LBS camera phone apps is not without a degree of caution. As somebody working in the creative industries, Barbara is mindful of how images can be reappropriated and that not all information should be shared. Paralleling shifts in camera phone practices elsewhere in the Asia-Pacific region, Barbara often takes self-portraits just for her own memory rather than sharing them as was once the trend (Lee 2005; Hjorth 2007). Despite her love of geotagging, she sometimes chooses not to share her location when sharing an image.

Barbara's image practices are indicative of a shift in everyday mobile media users whose use of photography can no longer be understood as simply representing their connectedness in a network, but requires us to attend to the relationship between people, images and environment, that is to their situatedness in ecologies of place. While Barbara's ability to articulate her camera phone and locative media practices might be more representative of an early adopter, her comments do highlight shifts in the ways in which visuality, place and intimacy are overlaid. Situated as such people make choices about whether to share information about a locality and the types of social relations and experiences they open up to. They are working on how to make their temporal, spatial, social and geographic movements as part of everyday media practice. In-between places like trains, busses or the walk between one building to another are no longer contexts for just 'killing time'. These wayfarer spaces, as 
an embedded part of everyday life, have now become key moments where new forms of visuality (Ingold 2007) and sociality are generated, through camera phone photography and the digital copresence associated with locative media.

The rise of locative media, characterized as using Global Positioning Systems (GPS), can be viewed as part of smartphone convergence with mobile and social media. With the uneven rise of smartphones across the world, mobile media are increasingly becoming sites for growing social media use like Facebook Home and LBS like Google maps and Foursquare. Across numerous technical platforms, personal and cultural contexts, and through a wide variety of social media, people young and old are using social, locative and mobile media to rehearse earlier and, at the same time, create new forms of intimacy. Mobile social media are a global phenomenon, but they are also local at every point (Hjorth and Arnold 2013). Moreover, they require us to consider the relationality between online and offline localities. The ways in which locative media ongoingly overlay and entangle information and media with location invites us to conceptualize the relationality between these technologies and the environments of which they are part through Doreen Massey's (2005: 130) notion of place as being made up of "stories-so-far".

Sharing these ambient images among physically absent yet electronically co-present friends gives Soo comfort and joy. The sharing allows her to share moments-emotional gestures in a particular time and space-with friends in other co-present spaces. So, while Soo is located physically in a café she also simultaneously inhabits online localities whereby physically absent friends are "absent presences" (Gergen 2002). These new forms of co-presence are, through the emergent narratives and trajectories of camera phone photography not simply about being 'connected' but as we will show in this article they are characterized, made and experienced through forms of visuality through which the online/offline 
are entangled and relational.

The two moments in everyday mobile media practice we have opened this article with are examples of the millions of intimate media vignettes across the world that are at once photographic, social, locative and mobile. While there are many ways in which to differentiate how camera phones are used across cultural, national, generational, gendered and other markers of difference, these remain common themes. They are photographic in that camera phone photography has become part of the everyday reality and visuality of the people whose experiences they describe. As outlined elsewhere (anonymous) this involves the ongoing navigation of a world that is both photographically represented and digitally mapped, and perpetually representable through the making of photographs. Yet there is a certain non-representational quality of the experience of camera phone photography.

These moments are social in that these media facilitate public and interpersonal interaction; they create forms of digital presence and co-presence, which are increasingly acknowledged as part of contemporary cultures and societies (Richardson and Wilken 2012). They are also locative in that this social and visual communication is geographically placed, both materially in that it happens in experienced material and sensory environments but also in that it is placed digitally; in both senses the way it is placed situates it relationally. Finally these moments are mobile; they are taken as people who are always in movement, move through their environments, and they get caught up in the movements of others. Yet they are also mobile in the very sense that they are made by mobile technologies, that are ever-present in that they move with people and make possible the very making and experiencing of the emplaced sociality and visuality that characterizes locative media use.

Existing research has shown us that from Google Maps, geotagging, Foursquare and Jiepang, LBS is 
becoming an integral part of the smartphone (and shanzhai or copy) phenomenon. However, the uptake of LBS has been uneven across a variety of factors such as culture, age and temporal differences. The more locative media becomes a key part of media practice, the more the way in which we conceptualize and understand the complexity of place shifts (Wilken and Goggin 2012). Locative media not only transforms how we experience mobility (technological, geographic and psychological) but also how this shapes the fabric of what we see as constituting place. Yet there remain gaps in our knowledge about how locative media is becoming part of the personal worlds of its users. In particular we know little about the impact it is having upon people's livelihoods, privacy and identity (Cincotta and Ashford 2011; Perusco and Michael 2007; Gazzard 2011) in everyday life. Existing discussions have focused on art, innovation and experimentation (de Souza e Silva and Sutko 2009; Hjorth 2010, 2011; Wilken 2011). However there remains a dearth of nuanced research on locative media that provides in-depth, contextual accounts of its socio-cultural dimensions in everyday mobile media practice and how new forms of co-presence and place are increasingly experienced through the use of mobile apps. In this article we advance research in this area by examining these issues, through a focus on the question of how the new digital cartographies, photographic practice, co-presence and the emerging stories of place are taking on novel dynamic dimensions. We consider the unevenness of LBS in the uptake despite the rhetoric of it becoming mainstream.

Through a preliminary study of ten users of smartphones in urban Australia we explore their everyday routines and how camera phone and LBS practices become part of everyday routines and repetitions. Australia has been quick to take up smartphones with ACMA noting that in 2013 mobile internet subscriptions have now reached 22.1 million: basically one subscription for every person in the country (ACMA 2013). Through scenarios of use diaries, interviews and hanging out with these users, we have explored some of the ways in which camera phones are used to overlay place and intimacy. In the face 
of the rhetoric of LBS uptake we also explore the realities of LBS in the overlay of camera phone practices in everyday life.

In this article, we reflect how the shift from first to second generation locative media practices and emerging contemporary camera phone practices are becoming entangled to create new ways of representing, making and experiencing everyday online/offline environments overlaid with various forms of socialities. We propose that the overlay between camera phones and locative media that these new media practices create constitutes specific forms of situatedness and relationality between people and things that can be understood through a theory of emplacement. It simultaneously, as Richardson and Wilken have emphasized, generates various modes of presence-such as tele-, net- and copresence-which they associate with practices of place making (2012). These forms of presence, we suggest can be understood through a notion of sociality, that focuses on the qualities of social relationships (see Pink 2008), which are we argue, are made through the intersection of camera phone photography and locative media practices described above.

These key shifts raise a series of conceptual and methodological questions concerning undertaking studies of media in situ, which, we argue, need to be accounted for in mobile and locative media studies. The two examples of mobile media practice we have described above are examples of what we have called elsewhere 'digital wayfaring' (2013). Drawing on Tim Ingold's notion of wayfaring (2007), we have proposed an understanding of the perpetual oscillation between online/offline co-present spaces within everyday life through the concept of the 'digital wayfarer'. This concept puts a theory of movement at the centre of our understanding of contemporary media practice. Rather than movement being between nodes in the 'network', we argue that movement is central to the way people and images become emplaced. 
Departing from first generation camera phone studies that defined visuality in terms of the network and thus camera phone images as snapshots or 'freezing time', through contemporary camera phone practices-characterized as second generation with their LBS features-images become part of the entanglement of place. We suggest that to understand how forms of co-presence and place-making are emerging we need to attend to the role of camera phone photography as both practice and as productive of forms of emplaced visuality whereby the user is conceptualized through the notion of the digital wayfarer.

In the next sections we first build on our existing work to develop further our understanding of the figure of the digital wayfarer and how she or he is implicated in the making of emplaced visualities and socialities. We then outline the methodological issues that arise when seeking to understand her or his world before discussing how these concepts can enable new and innovative understandings of the ways that camera phone photography (both deploying LBS and not) is becoming part of our everyday worlds.

\section{The Digital Wayfarer: A new way to conceptualize and research camera phone users}

The use of camera phones and other mobile media is in many ways characterized by movement. Here by movement we refer to an abstract notion or a concept of movement as much as to the mobile, moving nature of the way that people characteristically live and go about their business in the world. By movement we refer to the idea that we inhabit and at the same time are creating a world in movement, an ongoingness that we contribute to through our own mobility and that of which mobile media play an increasingly inevitable part. If anything, the study of mobile media has made the centrality of mobility to human life increasingly obvious, and in doing so invites us to turn to theories of movement as ways to conceptualize what is happening in digital worlds. 
We might then think of the ways that numbers of mobile media users perpetually move, around through the environment, each making their own physical and digital trace; or, as the anthropologist Tim Ingold would put it, creating lines through the world (Ingold 2007). Although Ingold himself does not apply his ideas to the study of mobile media, his work more broadly (see Pink 2012; Moores 2012) offers an important and novel route through which to comprehend how digital media are part of everyday environments. In the case of mobile media, Ingold's concept of the wayfarer offers us an interesting and novel way in which to consider the ways that the mobile nature of locative media becomes part of the ways that people make and live their online/offline worlds. For Ingold the mobility of the wayfarer is what makes the meshwork of place, he describes how:

... the path of the wayfarer wends hither and thither, and may even pause here and there before moving on. But it has no beginning or end. While on the trail the wayfarer is always somewhere, yet every 'somewhere' is on the way to somewhere else. The inhabited world is a reticulate meshwork of such trails which is continually being woven as life goes on along them (Ingold 2007: 84).

Ingold in fact contrasts wayfaring to what he calls transport (Ingold 2007). Our interest here is in the types of camera phone photography that form part of the wayfarer's route, however often in the context of travel that might conventionally be thought of as transport. Indeed we suggest that the very possibility of taking camera phone photos enables types of wayfaring in that it becomes part of the way that our trails and traces become 'somewheres' as we move through the world. As such, train and car journeys can be characterized by forms of wayfaring. Yet the digital wayfarer as we conceptualize her or him does not simply weave her or his way around the material physical world. Rather, their trajectory entangles online and offline as they move through the weather and the air, 
with the ground underfoot and surrounded by people and things, while also traversing digital maps, social networking sites and other online elements. They thus make places that are at once online and offline places through these movements and their photographic representations of them, which also traverse and connect the materialities and sensoriality of the experience physical world with the experience of being online.

We would emphasize that the digital wayfarer, is a theoretical construct, a descriptive category and not an empirical reality. However below we will show how using this category to analyze the reported written and photographic experiences of participants in our research as they weave their ways through their worlds, opens a productive lens onto the question of how the new generation of camera phone technologies and apps is changing and/or making new ways of being (with people and amongst things) in the world.

\section{Visuality and Sociality: from network to emplacement}

Above we have already alluded to how the movement of the digital wayfarer, contributes to the making of places. In the previous section we emphasized the visuality of the digital context as constituted through digital maps and the use of camera phone images. This is not to argue that we live in a world dominated by a visual sense (see Pink 2009, 2012) but rather to call for attention to the ways in which digital photography is becoming part of the ways that environments and socialities are experienced, made, and represented in a world where the online/offline are part of the very same places. As Pink has argued, photographs are not simply about what is represented in them, but they are emergent from what was above, below, infront and behind. They stand for not just the thing or person that they depict, but the trace made through the world by the photographer who has produced them (Pink 2013). 
In the last section we emphasized movement. Photographs have in this sense long since been made in movement; that is by a moving photographer photographing a moving world (see Pink 2011). Yet camera phone photography invites us to consider the ways that the technologies and the images themselves are implicated in movement in new ways-because it suggests we need to account for the ways that place is constituted at the intersection between the online and offline and the ways that photographic images in this context come to constitute what we call an emplaced visuality. That is, a visuality that is part of place and makes place, and in this case traverses and connects the materialphysical with the digital-intangible.

To conceptualize camera phone photography as co-constitutive of place, however we need a clear theory of place. Above we have stressed that the concept of the digital wayfarer is not that of a real person, but an abstraction that helps us to analyze the types of experiences that our participants relate to us. Likewise place as we use the concept here is an abstraction, it does not refer to actual localities or online configurations, but acts as an organizing concept with fluid boundaries through which we can view and consider different configurations of online/offline combinations and the threads of sociality and visuality that traverse them. Place, therefore as conceptualized here follows Doreen Massey's notion of place as 'open', a 'constellation of processes' forever in movement, changing and unfinished (2005). Place is moreover, when used analytically, constructed further through the intentions and interests of the researchers and scholars who themselves write and read about it. As researchers we gather together the components of place that we are concerned with for our analytical purposes, and we attend to these rather than privileging others. This has led Pink to write of what she calls 'ethnographic places' to signify the ways that we construct our own objects of analysis and, how these are indeed reconstructed and added to when they are appropriated by our readers (Pink 2009). 
Such a concept of place is particularly useful for understanding how images become part of online/offline worlds. It allows us to account for how images begin to participate in these worlds not only through their roles in the digital and material environments of which they are part and which they emerge from and represent, but also, as we have shown in the opening examples of this article, the forms of sociality that emerge in worlds that incorporate the online and offline, making them part of the same analytical place. In combination with rendering the visuality of such places as equally digital and material, such digital photographs also play a role in creating the affective qualities of sociality that have come to be termed digital co-presence and are seen by some academics as characteristic of the qualities of 'place' as constituted in worlds where locative media are part of everyday life.

This re-thinking of camera phone photography through a theory of place also implies a theoretical move, away from the idea of networked visuality that has predominated in earlier understandings. The first generation of camera phones studies by the likes of Mizuko Ito and Daisuke Okabe (2006), noted the pivotal role played by the three ' $\mathrm{s}$ '— - sharing, storing and saving —in informing the content of what was predominantly 'banal' everyday content (Koskinen 2007). This included a focus on the role of networked sites like Flickr and YouTube (Lee 2005, 2009; Hjorth 2007; Villi 2010). Here a networked visuality exhibited the defining aesthetics of "common banalities" (Mørk Petersen 2009) and "vernacular creativity" (Burgess 2007). In contrast with the growth in LBS games like Foursquare, Jiepang (China) and I love Coffee (South Korea) that allow users to "check in" and upload pictures, we see the shift from networked visuality to a visuality that is better understood through concepts of emplacement and entanglement.

Concurrent with the shift in first to second generation camera phone studies has been the movement of LBS into the mainstream (Gordon and de Souza e Silva 2011; de Souza e Silva and Frith 2012; Farman 
2011; de Souza e Silva and Hjorth 2009). Although second generation LBS games like Foursquare are in their infancy, this is an area of growing diversity and complexity within mobile media and communication. In particular, LBS are changing how we visualize intimate cartographies though shifting camera phone practices. In this context, Jason Farman suggests the digital map is 'a social network that engages users as embodied interactors rather than disembodied voyeurs' (2010: 869). The combination of digital maps and its augmented reality are not purely visual (Lapenta 2011; Farman 2010), they are, as Pink suggests, about 'emplaced visuality’ (2011).

We have argued that the overlay of locative media with camera-phone photography should be understood as part of a continually shifting and emerging ecology of place where humans, the material and digital are increasingly entangled (Ingold 2008). This means a departure from the dominant 'network' paradigms in visual/media culture and internet studies, towards a focus on 'emplacement' whereby people, images and technologies are always situated, in movement and part of and constitutive of place (Pink and Hjorth 2012). As Ingold's work shows us, as we move through the places of which we are part, we also continually sense, and learn. Ingold argues that,

People do not "make sense" of things by superimposing readymade sensory meanings "on top" of lived experience, so as to give symbolic shape to the otherwise formless material of raw sensation. They do so, rather, by weaving together, in narrative, strands of experience born of practical, perceptual activity. It is out of this interweaving that meanings emerge (2011: 326)

The overlay between camera phones and locative media highlight the importance of movement in understanding place. As Pink has argued, locative media provide new ways in which to frame images with the 'continuities of everyday movement, perceiving and meaning making' (Pink 2011: 
4). By contrasting 'photographs as mapped points in a network' with 'photographs being outcomes of and inspirations within continuous lines that interweave their way through an environment - that is, in movement and as part of a configuration of place' (Pink 2011: 4-5), we can conceive of images as produced and consumed in movement.

Ingold's wayfarer is always on the move, making place as an inhabitant of his/her environment (2007). When we translate this idea into the task of understanding what people are actually doing with camera phones it enables us to consider how they encounter the online/offline world in various ways as they move through. As we have noted above however being on-line with locative media is often associated with forms of sociality, which scholars have referred to as digital presence and copresence. If we likewise consider wayfaring to have with its exploratory stance an element of sociality and thus understand moving through the world as inherently social as well as embodied and emplaced, we can make a theoretical connection between the visuality and sociality of the intersection between camera phone photography and locative media practices.

To trace how some of these emplaced socialities and visualities actually emerge in everyday life we present an example from one respondent's visual and written account, drawn from a preliminary study in which we asked a small group of ten Australians about their everyday camera phone practices in relation to locative media. We utilized scenarios of use diaries, interviews and hanging out to consider some of the ways in which camera phones were becoming a routine, 'wayfarer' part of everyday mobility. This sample group is part of a broader study we are conducting into cross-cultural and intergenerational uses of locative media in Melbourne, Tokyo and Shanghai. 
In this preliminary study we have asked ten smartphone users in Australia about their usage of camera phones and locative media relates to place and sociality. For many of these users, the acquisition of the smartphone has been marked by a sudden embrace, sometimes unwillingly, of locative media. However, there is also resistance to LBS as highlighted by Barbara's quote about choosing when to use and not deploy LBS. In this paper we explore the play and overlay between camera phones and locative media as part of a movement towards what we call emplaced visuality. For the purposes of this paper, we have focused upon two of the most articulate respondents to highlight how contemporary camera phone and LBS are part of broader emplacement narratives within everyday life.

\section{Mobile media user as the wayfarer}

Michelle's everyday overlaying of locative media and camera phone practices provides a good example of how the making and posting images are part of the way place is made and experienced. As discussed elsewhere, Michelle's use of mobile media technologies as she moves through her everyday world is indicative of Ingold's notion of 'wayfaring', whereby the travelling spaces are viewed as moments for active creativity and play — as demonstrated through her camera phone sharing.

Michelle, a 45 year old single mother, sums up her everyday locative and social media use, showing how different platforms, materialities, invisible elements of the environment (coverage) interweave as she goes through the day. She creates a strand of her life that is both rooted in embodied and affective experience of an everyday world, but at the same time digital and partially public:

I use FB too much and use it for a variety of reasons now, I use Twitter like a newspaper because it's too fast for me now and I lose track of the conversation threads too quickly. I like the speed of Facebook better. My use of Facebook is too frequent, at least 5 times a day. They are often my departure points. Eg Quick scan with my cuppa in the morning, 
surf it a couple of times when I'm commuting (depending on coverage availability) check messages when I check my email on arrival to work, lunchtime, when I leave etc. I normally post at night, depending on what I'm doing. I know this is not good for the psyche but I continue to do it anyway. Perhaps it's connected to something I've quietly named 'busy loneliness'. The other way I use it is to regularly add to my Instagram (ah nostalgia) which I simultaneously post to Facebook, twitter, depending on the image. The visual diary aspect really appeals to me. The timeline aspect of Facebook is also very seductive. I used to keep a diary, but now I keep my diary in public and in a cloud.

Michelle is an evocative writer, which is one reason why we have chosen her example to call attention to how locative media, photography and web platforms can become part of the entanglement of everyday life. Her words offer us a route through which to understand her everyday trajectory, her own feelings through this and the sensations that this brings: the cup of tea with Facebook in the morning, the tempo of Facebook feeling better than that of twitter, the "busy loneliness' of night time postings, and the sense of a historicity to her time on/offline in the timeline of Facebook.

We begin to get a sense of how it is to be a digital wayfarer by being invited into her descriptions and connecting to them through our own experiences. This embedding of social media and photography into everyday life coincided with what another respondent told us when she described how her life had changed when she got a smartphone: 'Definitely more anxious checking of Facebook. More posting of iPhone photos on Facebook. I downloaded a range of aps that I use as social lubricants: nothing perks up a difficult social encounter more than fatify!' While as researchers and readers we may not be engaging in exactly the same practices as these participants, 
we have a sufficient basis of experience to be able to try to imagine some of the embodied and affective forms of engagement they describe.

We also asked respondents to describe how they had taken photographs with their camera phones that had been particularly meaningful to them. Michelle, like our other respondents wrote about how she had taken photographs on the move (Figure 2).

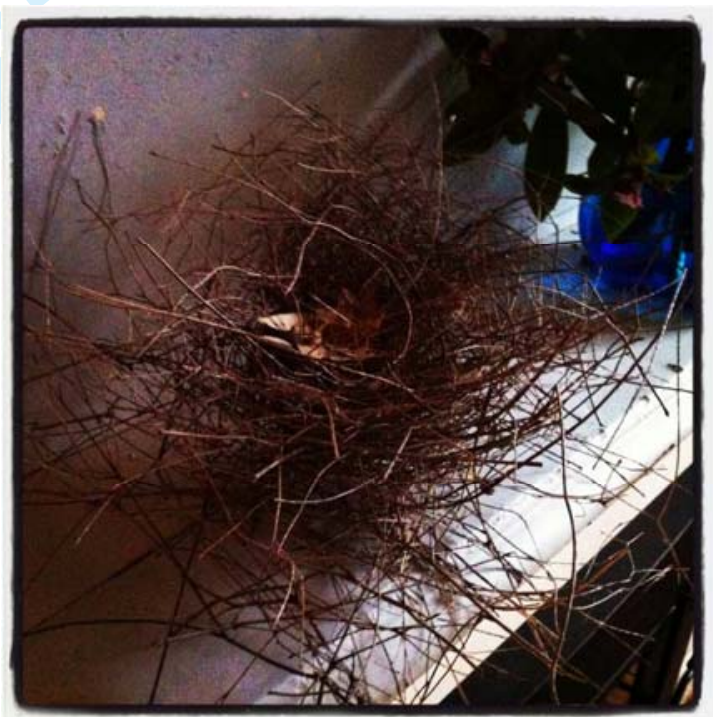

Figure 2: This bird may be homeless but she is a true artist

I was rushing out the back door, with the rubbish, on the way to kindy (kindergarten) with the boy, then the train, then work. When I opened the door there was the beautiful birds nest on my doormat (a very windy stormy night), It was such a showstopper, such a talented bird, so delicate and vulnerable but also cosy and warm. I immediately affiliated with the bird's dilemma, and I was also very inspired by its beauty. I wanted to stay home. I didn't want to travel. I didn't know which tree it was from so I took it inside and put it on the mantle. After taking a couple of snaps, the boy and I took off towards our day. The train is my precious 
thinking time and during the commute (I think it was Gisbourne) I decided to post it to instagram/FB/twitter with the title 'This bird may be homeless but she is a true artist'. The post received quiet a few likes, mostly from artist friends that I'm currently or about to start working with. Some random comments too. My house is my home and it's as organic and changing as my garden. This wasn't my way of thinking over the last year or so, but the shift has occurred and the nest landed on my doorstep.

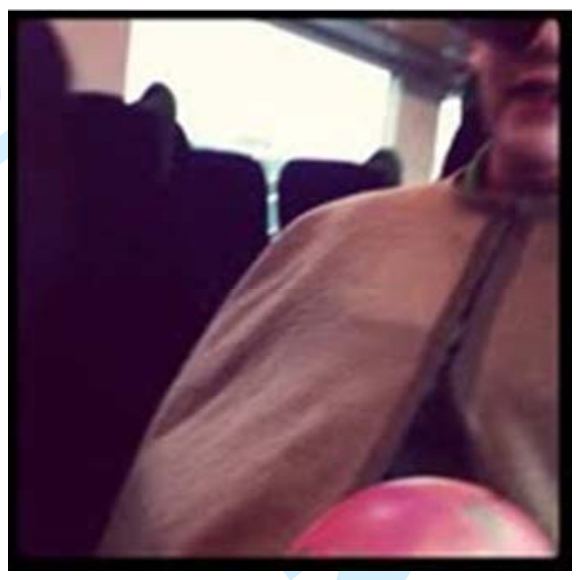

Figure 3: lost and found

In Figure 3 Michelle talks about her and her son's play with a camera phone app, Instagram, while on a train commute to meet a friend. Along with featuring a plethora of filters, many of which make the images look analogue and 'retro', is the ability to geotag and share across a variety of networks almost simultaneously. Taken by her son and geotagged via Instagram, Michelle's obscured features became a representation of their 'in-between' and confined conditions while on route to a meeting. As Michelle states,

Another commute, this time the boy and I were going down to Fed Square to meet a dear friend, a heart person that I only get to see every couple of years or so. He was hassling me with txts like 'where are you?, when will you get here?' etc and my boy 
and I were reading stories, playing games on the iPhone and taking silly pictures of each other. Rather than respond to his txts I posted an image my boy took, only on instagram so he would understand that we were on a train and in commute. Which he did. But I don't think the geo-tag worked.

For the aforementioned respondent Barbara, Instagram is a preferred camera phone app that allows her to choose when she wants to geotag and affords her control over her audiences. She enjoys the retro lenses provided by Instagram and often uses these filters to create a feeling of another period in time. These retro aesthetics can be viewed in her Instagram of a bowling game (Figure 4). Unlike pessimistic social commenters like Robert Putman who encapsulated what he saw as the declining in social capital (welfare) through the analogy of "bowling alone", Barbara shows how mobile media can invite co-present friends to join in on the action.

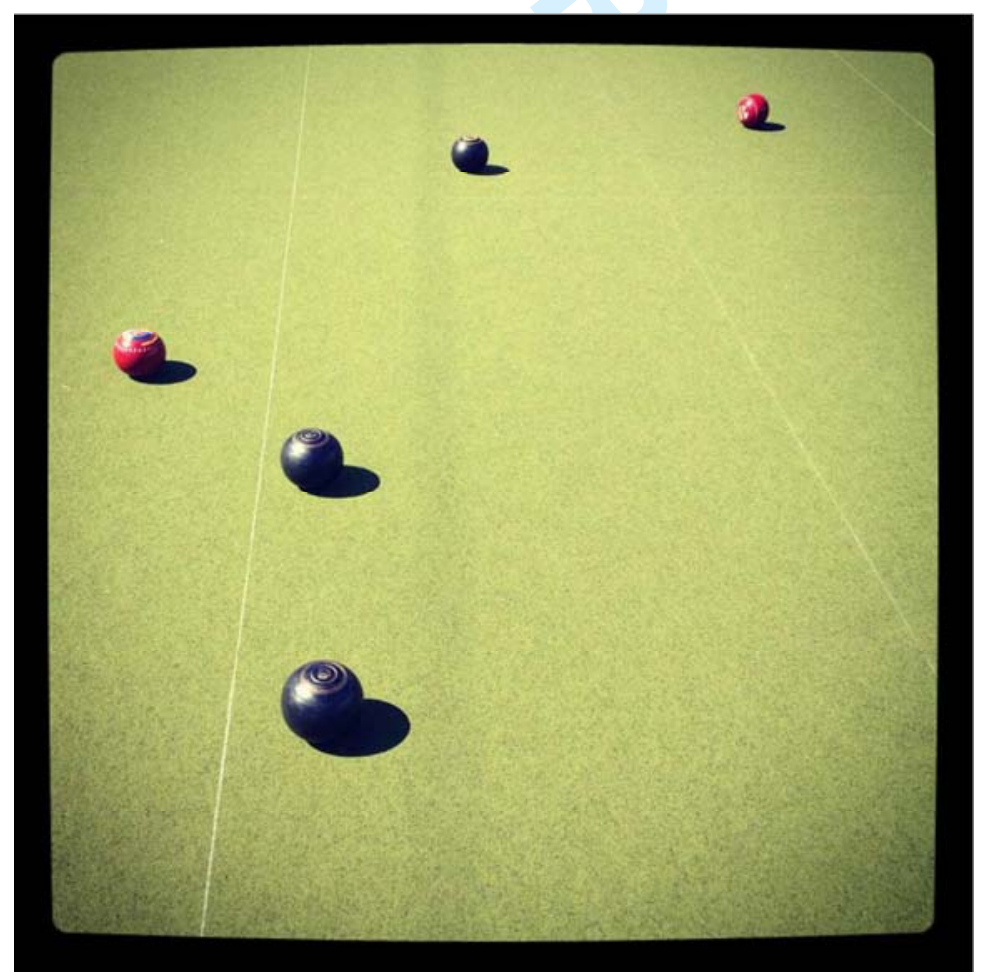

http://mc.manuscriptcentral.com/MMC 


\section{Figure 4: "Lawn Bowls in Thornbury. A perfect November Day". Barbara shares a bowling moment with co-present friends}

The idea of the mobile media user as a digital wayfarer is clearly addressed by Barbara in her playful pictures 'on the move'. In Figure 1 we see a great example of emplaced visuality whereby the image is part of the everyday movements. Michelle too sees the movements to places as not just in-between spaces but places for active creativity as epitomized in Figure 3 (an Instagram taken by her five year old son). Rather than Michelle's movement on route being viewed as a waiting time in need of filling in, Michelle sees this moments as times for play and creativity in which locative media and camera phones feature. Rather than commutes on trains being devalued as periods for 'killing time', through the use of camera phones and locative media a play between place, movement and sociality is formed.

These examples are indicative of what we have defined as emplaced visuality. That is, rather than just being about networked visualities in which movements through space, time and place is frozen into a networked snapshot to share, emplaced visualities are about an embracement of camera phone images as a co-present part of movement through place and spaces. Spaces like trains are no longer about a transitory 'in-between' space whereby the destination is the most important place; rather, spaces like trains become incubators for the wayfarer. They become about co-presence rather than co-location (Beaulieu 2010). These emplaced visuality in turn highlight the ways in which cartographies of the social, spatial and geographic are being emplaced and entangled in new ways. Through these changes, we need to adapt models for analyzing such media practices as part of emplaced cartographies that see location, representation and experience being transformed through mobile media. 
Our study highlights the ongoing significance of co-presence within mobile media practices. From the work of Christian Licoppe (2004) and Mimi Ito (2003), the impact of presence as a crucial concept in mobile communication and internet studies has been amplified in an era of smartphones (Hjorth, Wilken and $\mathrm{Gu}$ 2012). Here it is important to recognize that all forms of presence (including face-to-face) and intimacy are mediated: if not by technology then by language, gestures and memories (Hjorth 2005; Mantovani and Riva 1998). Licoppe's work has long been committed to the exploration of the ways in which face-to-face absence can be made present through a variety of ways, so much so that it is best to eradicate boundaries between absence and presence instead for a notion of "connected" presence (2004). This interest has been furthered in Licoppe's work on LBS games like Mogi in Japan and more recently Foursquare in Paris in which he outlines how existing and emergent forms of sociality and etiquette are adapted across and inbetween the gamic spaces.

For Ito in her study of Japanese youth, the term "augmented co-presence" can help make sense of these complex absent/present communicative interactions, and how they can lead to "new senses of place being constructed as a hybrid between co-located and remote social contact" (2003). Debates around the various states of presence (co, net, tele) have become amplified in the case of the smartphone with its app ecology providing various uneven forms of being in the world across embodied, disembodied and distracted modes of engagement. As Ilkka Arminen's (2006) observes, social context rather than "pure geographical location" is generally of greatest interest to the user as a motivation for social media use. 
Spaces for 'mobile stillness' (Bissell and Fuller 2011) like trains were seen as an important place for reflection, exploration and play. In short, an everyday space for creative incubation. Transport spaces — as part of the everyday wayfarer routines and mobilities—have a long history in providing a reflection space, however, with the rise of mobile media this socio-spatial environment takes on new configurations, especially in terms of multiple forms of co-presence (here/there; virtual/offline). As a space that, through its perpetual movement, still evades being geo-tagged, the train provides an insightful place for contemplating the everyday and intervening mobility with immobility or "stillness" (Bissell and Fuller 2011). Over the past decade, especially through the sociological exploration around "mobilities", the site of train and transport more generally has gained importance as a site for incubation and reflection. For David Bissell and Gillian Fuller, these transitory and yet paradoxical spaces might be best understood through the notion of "stillness in a mobile world" (2011). For Rowan Wilken in "Seen from the Carriage: A Rhythmanalytic Study of Train Travel and Mediation" (2012), the train space can be understood by deploying Lefebvre's "rhythmanalysis" method. For Wilken, the modern suburban train carriage negotiates,

... a dynamic environment of physical (and "virtual") co-presence that involves complex forms, layerings, and negotiations of different kinds of mediation, including windows (as both mirror and screen), audio public address systems (operates by driver or station staff), analog media (print publications of various forms, as well as advertisements), and digital media technologies (MP3 players, mobile telephones, laptops, train carriage LED displaces), and other personal items (makeup compacts, glasses) (Wilken 2012: 92).

For our ten respondents, the routine of transport provided unaccounted spaces for them to reflect upon theirs and others camera phone images. Unlike workspaces in which they might feel guilty to 
partake in camera phone play, the routine space of transport played an in-between space between work and home for them to do the 'work' of non-work playbour (what Julian Kücklich calls play labour). For example, for Michelle, at home she would be too busy with housework and cooking; at work, her time too stretched to play with her mobile. Moreover, as transitory spaces that eschews the mobile and immobile, public and private, transport like trains have played a key role for co-present media from novels and newspapers in the nineteenth century to mobile phones in the late twentieth and early twenty-first century.

Let us return to Michelle's comments about camera phone taking and sharing predominately on the train. Michelle's comments allow us to follow the image from the moment before it was produced, to the ways it enabled her to imagine and to reflect on her home, how it came to matter to her during her commute on the train, to its posting on Facebook and the socialities that it became part of in that context. Here we see a form of everyday wayfaring in which co-present online/offline spaces are part of the same configuration of place. As she wayfares Michelle attends to those things that matter as they emerge, and she writes about how she creates correspondences between them. Through the narrative of the trajectory of the photograph the story brings together the affective, material, social and temporal elements of the routines and rhythms of everyday life. Michelle focuses on articulating the nodes and entanglements rather than the destination. This is the technique of the wayfarer. Her camera phone locates her within the tapestry of everyday life as well as providing a co-present vehicle for her friends to accompany her.

We had purposefully asked participants to tell us about images that were particularly meaningful to them. Both Michelle and Barbara use their discussions of the images to reflect on their own inner states and aspects of their lives and environments. As we have suggested elsewhere, while on the 
one hand these images can be understood within the context of existing discussions about personal photography, camera phone photography in fact represents something rather different (Pink and Hjorth 2012). These examples demonstrate some of these elements of departure and mobilityperhaps most obviously in that camera phone photography is taken as we go through and as we interweave online/offline worlds. It also becomes part of online entangled socialities.

\section{Conclusion on the Move: Emplaced and entangled}

As part of the smartphone phenomenon, LBS games are accompanied by an accelerated rate of camera phone taking, editing and sharing. The new overlays of locative and social media with the rise of photo apps and high quality camera phones, has seen new forms of co-present visuality that overlay and interweave online and offline cartographies in different ways. Far from banal acontextualized images, these pictures deploy the newest of filters and photographic tricks to give a sense of the poetic and unique and are then overlaid electronically onto places. This is not a mere practice of networked visuality as noted by the first studies into camera phones, rather we see an emplaced visuality that creates, and reflects, unique forms of geospatial sociality. However, as we have seen, the uptake of LBS in camera phone practices is far from homogeneous with some resistances (such as Barbara's comments) apparent.

The traces made as camera phones are used, as mobile media weaving through material/digital environments with their users (as wayfarers) thus become forms of visuality that are emplaced digitally, socially and materially. Their visual content is the outcome of the multiple constituents of place through which they are produced and in relation to which the body of the photographer is emplaced-including the weather, social relationships, localities, software and code, technologies and human innovation and creativity. They are more over not produced by lone participants 
making their ways through the world in a solitary way, but more often than not characterized by several of the forms of co-presence that we have discussed above. These are felt, affective and embodied realities where people's embodied engagements, social relationships and ways of moving with camera phones should be coming into our focus as researchers.

In this paper we have proposed an understanding of camera phone photography as part of a continually shifting and emerging ecology of place where humans, the material and digital are increasingly entangled. This, we argue, signifies a need to depart from the dominant 'network' paradigms in visual/media culture and internet studies, towards a focus on 'emplacement' and copresence, whereby people, images and technologies are always situated, in movement and part of and constitutive of place.

\section{Acknowledgements}

The notion of the digital wayfarer was initially developed in our earlier short book chapter, The digital wayfarer: Reconceptualizing camera phone practices in an age of locative media, in G. Goggin and L. Hjorth's (eds) The Routledge Mobile Media Companion. NY: Routledge.

This article is a significantly revised and expanded development of the ideas represented in that chapter, however some parts of the original work remain here, including the example of 'Michelle' (pp 15-22).

\section{References}

ACMA (Australian Communications and Media Authority) (2013) Report 3-Smartphones and tablets: Take-up and ins Australia, 
http://www.acma.gov.au/webwr/_assets/main/lib310665/report-3-smartphones_tabletssummary.pdf

Arminen, I. (2006.) Social Functions of Location in Mobile Telephony, Personal and Ubiquitous Computing, 10(5), July: 319-323.

Beaulieu, A. (2010.) From co-location to co-presence: Shifts in the use of ethnography for the study of knowledge. Social Studies of Science 40 (3): 453-470.

Bissell, D. and G. Fuller (eds) (2011) Stillness in a Mobile World, London and New York: Routledge.

Burgess, J. E. (2007.) Vernacular creativity and new media (Doctoral dissertation). Retrieved from http://eprints.qut.edu.au/16378/

Casey, E. (1996.) How to get from Space to Place in a fairly short stretch of time. In S. Feld and K. Basso (Eds) Senses of Place. Santa Fe, New Mexico: School of American Research Press, pp. 1352.

Cresswell T. (2010.) Towards a politics of mobility. Environment and Planning D: Society and Space 28(1): 17-31.

Cincotta, K. and Ashford, K (2011.) The New Privacy Predators. Women's Health Nov. URL $\begin{array}{llll}\text { (consulted } & 10 & \text { January }\end{array}$ http://www.purehacking.com/sites/default/files/uploads/2011_11_00_Australian_Womens_Health November.pdf

de Souza e Silva, A. and Frith, J. (2012.) Mobile interfaces in public spaces: Locational privacy, control and urban sociability. New York: Routledge.

de Souza e Silva, A. and Hjorth, L. (2009.) Playful Urban Spaces: A Historical Approach to Mobile Games. Simulation and Gaming 40(5): 602-625. 
Gómez Cruz, E. (2012) De la cultura Kodak a la imagen en red: una etnografía sobre fotografía digital. Barcelona: Editorial UOC.

Farman, J. (2011.) Mobile Interface Theory. London: Routledge.

Gazzard, A. (2011.) Location, Location, Location: Collecting Space and Place in Mobile Media. Convergence: The International Journal of Research into New Media Technologies, 17 (4): 405417.

Gergen, K. (2002.) The Challenge of Absent Presence. In Perpetual Contact: Mobile Communication, Private Talk, Public Performance, eds. J.E. Katz \& M. Aakhus, Cambridge: Cambridge University Press.

Gordon, E. and de Souza e Silva, A. (2011.) Net Locality. London: Wiley-Blackwell

Hjorth, L. (2005.) Postal presence: the persistence of the post metaphor in current SMS/MMS practices, in Fibreculture Journal, issue 6: Mobilities, New Social Intensities and the Coordinates of Digital Networks, http://journal.fibreculture.org/issue6/

Hjorth, L. (2007.) Snapshots of almost contact. Continuum, 21 (2): 227-238.

Hjorth, L. (2009.) Mobile Media in the Asia-Pacific: Gender and the Art of Being Mobile, London/New York: Routledge.

Hjorth, L. (2010.) The politics of being mobile: a case study of a different model for conceptualizing mobility, gaming and play, in Digital Cityscapes, (eds) A. de Souza e Silva \& D. Sutko, New York: Peter Lang Group, pp. 83-99.

Hjorth, L., (2011.) Locating the Online: Creativity and User Created Content (UCC) in Seoul, South Korea, Media International Australia, No.141: 128-136.

Hjorth, L. and Arnold, M. (2013.) Online@AsiaPacific. New York: Routledge. 
Ingold, T. (2008.) Bindings against boundaries: entanglements of life in an open world. Environment and Planning A 40: 1796-810.

Ingold, T. (2007.) Lines: A Brief History. London: Routledge.

Ito, M. (2003) Mobiles and the Appropriation of Place, Receiver, 8, http://academic.evergreen.edu/curricular/evs/readings/itoShort.pdf.

Ito, M., and Okabe, D. (2006.) Everyday Contexts Of Camera Phone Use: Steps Towards Technosocial Ethnographic Frameworks. In J. Höflich and M. Hartmann (Eds.) Mobile Communication In Everyday Life: An Ethnographic View, Berlin: Frank and Timme, pp. 79-102.

Lapenta, F. (2011.) Locative media and the digital visualisation of space, place and information, Visual Studies, 26(1): 2011: 1-2.

Lee, D-H. (2005.) Women's creation of camera phone culture. Fibreculture Journal 6, URL (consulted 3 February 2006) http://www.fibreculture.org/journal/issue6/issue6 donghoo_print.html

Lee, D-H. (2009.) Re-imaging urban space: mobility, connectivity, and a sense of place. In G. Goggin and L. Hjorth (Eds.) Mobile technologies, London/New York: Routledge, pp. 235-251.

Licoppe, C. (2004.) 'Connected' Presence: The Emergence of a New Repertoire for Managing Social Relationships in a Changing Communication Technoscape, Environment and Planning Design: Society and Space 22(1): 135-156 (135).

Lorimer, H. (2005.) Cultural geography: the busyness of being "more than representational". Progress in Human Geography 29(1): 83-94 
Mantovani, G. and Riva, G. (1998) 'Real' Presence: How Different Ontologies Generate Different Criteria for Presence, Telepresence and Virtual Presence, Presence: Teleoperators and Virtual Environments, 1(1): 540-550.

Massey, D. (2005.) For Space. London: Sage.

Mørk Petersen, S. (2009.) Common Banality: The Affective Character of Photo Sharing, Everyday Life and Produsage Cultures, PhD Thesis, ITU Copenhagen.

Moores, S. (2012.) Media, Place and Mobility. London: Palgrave Macmillan

Perusco, L \& Michael, K. (2007.) Control, trust, privacy, and security: evaluating location-based services. IEEE Technology and Society Magazine, 26(1): 4-16. http://ro.uow.edu.au/cgi/viewcontent.cgi?article=1521\&context=infopapers $\quad$ Accessed 9 April 2013)

Pink, S. (2008) 'Re-thinking Contemporary Activism: from community to emplaced sociality' in Ethnos 73(2): 163-188

Pink, S. (2011.) Sensory digital photography: re-thinking "moving" and the image. Visual Studies 26(1): 4-13.

Pink, S \& L. Hjorth (2012.) Emplaced Cartographies: Reconceptualising camera phone practices in an age of locative media. Media International Australia, 145: 145-156.

Pink, S \& L. Hjorth (2014.) The digital wayfarer: Reconceptualising camera phone practices in an age of locative media, in G. Goggin and L. Hjorth's (eds) The Routledge Mobile Media Companion. NY: Routledge (forthcoming) 
Richardson, I. \& R. Wilken (2012.) Parerga of the Third Screen: Mobile Media, Place, and Presence. In R. Wilken \& G. Goggin (Eds.) Mobile Technology and Place. New York: Routledge, pp. 198-212.

Villi, M. (2010.) Visual mobile communication: Camera phone photo messages as ritual communication and mediated presence. Academic dissertation. Aalto University School of Art and Design, Helsinki.

Wilken, R. (2012) Seen from the Carriage: A Rhythmanalytic Study of Train Travel and Mediation, in B. Fraser and S. Spalding (eds) Trains, Culture, and Mobility: Riding the Rails. Maryland: Lexington Books.

Wilken, R. (2012.) Locative media: From specialized preoccupation to mainstream fascination. Convergence journal 18(3): 243-247. 